\title{
Distribution and Risk Assessment of Polycyclic Aromatic Hydrocarbons in Vegetables Grown in Pakistan
}

\author{
Mohammad W. Ashraf, ${ }^{1}$ Syed Iqleem H. Taqvi, ${ }^{2}$ Amber R. Solangi, ${ }^{3}$ and Umair A. Qureshi ${ }^{3}$ \\ ${ }^{1}$ Department of Mathematics and Natural Sciences, Prince Mohammad Bin Fahd University, Al Khobar 31952, Saudi Arabia \\ ${ }^{2}$ Government Degree College and Postgraduate Centre, Hyderabad, Sindh 71000, Pakistan \\ ${ }^{3}$ National Center of Excellence in Analytical Chemistry, University of Sindh, Jamshoro 76080, Pakistan
}

Correspondence should be addressed to Amber R. Solangi; ambersolangi@gmail.com

Received 5 June 2012; Accepted 10 July 2012

Academic Editor: Athanasios Katsoyiannis

Copyright (C) 2013 Mohammad W. Ashraf et al. This is an open access article distributed under the Creative Commons Attribution License, which permits unrestricted use, distribution, and reproduction in any medium, provided the original work is properly cited.

\begin{abstract}
Distribution and risk assessment of eight priority polycyclic aromatic hydrocarbons (PAHs) contents have been examined in different varieties of vegetables grown in Pakistan. The results showed that the total PAH contents were higher for root vegetables like potato and carrot $(\sim 13 \mu \mathrm{g} / \mathrm{kg})$ and relatively lower for turnip $(10.9 \mu \mathrm{g} / \mathrm{kg})$, respectively while for the fruit vegetables, all the peels were found to be more contaminated than cores. The ratio of total PAH concentrations in peels with respect to those of cores is found to be $1.45,1.26,1.31,1.44,1.40$, and 1.36 for potato, turnip, carrot, eggplant, cucumber, and bitter gourd, respectively. For leafy vegetables, cabbage showed maximum PAH $(11.6 \mu \mathrm{g} / \mathrm{kg})$ as compared to the cores of fruit vegetables. Among individual PAH congeners, anthracene showed higher levels in all vegetables. For benzo(a)anthracene, maximum concentration $(3.44 \pm 2.10 \mu \mathrm{g} / \mathrm{kg})$ was encountered in turnip cores. Highest benzo(e)pyrene concentration was found in potato $(3.19 \pm 1.67 \mu \mathrm{g} / \mathrm{kg})$ followed by turnip $(2.74 \pm 1.22 \mu \mathrm{g} / \mathrm{kg})$. Benzo(b)fluoranthene and benzo(k)fluoranthene showed relatively lower levels in all samples studied. All the concentrations of PAHs are presented on a fresh weight basis. The results of human exposure of PAH by consumption of these vegetables showed that cumulative dietary exposure of Pakistani population to PAHs from vegetables ranges from $0.25 \mu \mathrm{g} / \mathrm{p} / \mathrm{d}$ to $1.16 \mu \mathrm{g} / \mathrm{p} / \mathrm{d}$.
\end{abstract}

\section{Introduction}

Environmental risk assessment of different food items is an important study for the healthy life of human beings. Vegetables are one of the most consumable food items in human diet because of their nutritional value. Contamination in vegetable may prove hazardous for a major portion of the population. There are three most dangerous groups of contaminants that may present in vegetables: polycyclic aromatic hydrocarbons (PAHs), pesticides, and heavy metals. PAHs are one of the most alarming indicators and threat to living organism if present in the food chain. PAHs are a persistent group of organic pollutants formed during incomplete combustion of fossil fuels and garbage. They are originated from both natural and anthropogenic sources, but major contribution is from later source. They are abundantly available in the environment and can remain there for decades. It is an established fact that dietary exposure to PAHs may develop different forms of cancer and also elevated levels of DNA adduct, mutation, and reproductive effects $[1,2]$. Several studies confirm the carcinogenicity of PAHs like: benzo(a)anthracene $(B(a) A)$, benzo $(b)$ fluoranthene $(B(b) F)$, benzo $(\mathrm{k})$ fluoranthene $(\mathrm{B}(\mathrm{k}) \mathrm{F})$, benzo(a)pyrene $(\mathrm{B}(\mathrm{a}) \mathrm{P})$, and dibenzo(ah)anthracene $(\mathrm{D}(\mathrm{ah}) \mathrm{A})$ [3]. The occurrence and sources of PAHs have been widely studied worldwide, since these compounds enter into the food chain through water, air, and soil [4]. The studies that present data for PAHs in Pakistan are only few. Recently a work has been reported for PAH analysis of a river in Punjab (Pakistan) [5]. The study provided a baseline data of $17 \mathrm{EPA}$ priority $\mathrm{PAHs}$ in the surface water of the Chenab River. The results demonstrated that PAHs levels were moderate to highly polluted, when compared to other reported studies of freshwater bodies, worldwide. 
PAHs occur as contaminants in different food varieties and beverages. The sources of PAHs in food are predominantly from environmental pollution and food processing steps. There are many studies showing uptake of PAHs by plants [6-8] and contamination of PAHs was often found in various food categories including vegetables [9-11]. In plants, PAHs are present mainly due to deposition of airborne particulates on their exposed surfaces. The waxy surface of vegetables and fruits is able to concentrate low molecular mass PAHs through surface adsorption and particle-bound high-molecular mass PAHs can contaminate the surface due to atmospheric fallout [12]. Moreover, despite their poor solubility in water, they can be taken up and bioaccumulated by plants. The main pathway for the accumulation of PAHs in vegetables is the gaseous deposition, and the emissions from the fossil fuels combustion was shown to influence the PAHs levels and profiles in vegetables and fruits grown nearby. In some cases, however, direct relationship between soil and plant PAH concentrations were also observed suggesting a possible pathway from contaminated soil to plant roots [13]. Zhang et al. [14] reported a concentration range of PAHs from 8,600 to $111,000 \mathrm{ng} / \mathrm{g}$ dry wt in Chinese vegetables. Another study conducted on comparison of polycyclic aromatic hydrocarbon uptake pathways and risk assessment of vegetables from waste-water irrigated areas in northern China. The study concluded that root or air uptake pathways are the dominant pathway and the dominance of one pathway over the other depends on the vegetable, contaminant, and local conditions [15].

The diet is certainly the major source of human exposure to PAHs [16], and the vegetables are the basic food in diet everywhere. The scientists and local authorities are very much concerned with the fact that how and to what extent PAHs are accumulated in the vegetables grown in agricultural areas. Extensive use of natural gas as fuel appears to be the most important reason for the prevalence of PAHs in the environment. Natural gas and furnace oil are common fuels used by industries and household applications. Owing to high cost of gasoline, compressed natural gas (CNG) is popular fuels in automobiles in Pakistan. However, so far, no viable efforts have been made in Pakistan to determine levels of PAHs in vegetables produced in major agricultural lands. This work analyzed the content of PAHs in nine important vegetables varieties which account for about $80 \%$ vegetables consumption in Pakistan, to calculate a preliminary estimation of the contribution of these vegetables as source of PAHs exposure to human beings.

\section{Experimental}

\subsection{Reagents}

Eight PAH congeners selected for this study were procured from Aldrich Chemical Company and Supelco Inc. (USA). Methylene chloride, acetonitrile (HPLC grade), and sodium sulfate were purchased from E. Merck. Doubly distilled, deionized water was used throughout the study.
2.2. Sampling. Punjab is the most populous province of Pakistan with approximately $60 \%$ of the country's total population and famous for its agricultural products. Lahore, the capital city of Punjab is highly urbanized and industrialized while a large portion of the fertile land in the surrounding area is used for agriculture and staple crops. Vegetables grown in this area supply the local as well as international markets. Nine varieties of vegetables: potato, turnip, carrot (root vegetable), cabbage, spinach (leafy vegetables), tomato, cucumber, eggplant, and bitter gourd (fruit vegetables) were selected. A total of 259 samples were collected and the sample's description is given in Table 1 . The samples were procured from local wholesale markets in order to have a clear picture of the levels of PAH and care was taken to grab samples grown in the lands of Punjab only. After purchase, the vegetable samples were bagged and kept refrigerated at $4^{\circ} \mathrm{C}$, till analyzed.

2.3. Sample Treatment. Fresh samples were washed with tap water, deionized water, air dried, and then carefully weighed. Potatoes, turnip, carrot, eggplant, cucumber, and bitter gourd were separated into peel $(<1 \mathrm{~mm})$ and cores with a normal kitchen peeler and carefully weighed. The concentrations of PAHs in peels and cores were determined separately. Cabbage, spinach, and tomato, were measured totally according to Pakistani dietary habits. For each vegetable, a composite sample of at least ten individuals was used (Table 1). All the composite samples were analyzed by triplicate. Dry matter content of the vegetables was measured by heating the samples at $95^{\circ} \mathrm{C}$ for 30 hours. After washing and peeling, the samples were chopped into small sections and homogenized in a blender mill.

2.4. PAHs Extraction from the Analyzed Samples. A $50 \mathrm{~g}$ of homogenized sample was mixed with 100 to $150 \mathrm{~g}$ (depending upon water content) of preheated anhydrous sodium sulfate and extracted with a mixed solvent (cyclohexane/acetone, 2:1) for 8 hours in a full glass Soxhlet extractor. The concentrated extract was purified by column chromatography on silica gel, as described by [10]. A glass column $(1.5 \mathrm{~cm})$ was packed with silica gel with anhydrous sodium sulfate $(7.5 \mathrm{~cm} \times 2 \mathrm{~cm})$, from top to bottom. The PAH extract was applied at the top of the column and eluted with $75 \mathrm{~mL}$ of methylene chloride. The clean extract was evaporated under gentle nitrogen flow and finally dissolved in $2 \mathrm{~mL}$ of acetonitrile.

2.5. PAHs Sample Analysis. Analysis was conducted on Alliance HPLC system by Waters Associates (USA), equipped with a UV detector $(\lambda=254 \mathrm{~nm})$ on ODs column $(5 \mu \mathrm{m}$; $250 \times 4.6 \mathrm{~mm}, 5 \mu \mathrm{m}, \mathrm{C} 18$ Waters PAH Column) at $30^{\circ} \mathrm{C}$. A mobile phase composed of acetonitrile-water $(75: 25 \mathrm{v} / \mathrm{v})$ at a flow rate of $1.5 \mathrm{~mL} / \mathrm{min}$ was used to separate the PAHs. Blank samples were prepared to prevent and detect the contamination during treatment operation [10].

During analysis, two injections of a mixture of PAHs standards were made every five pairs of vegetable samples to correct any possible variation in compound 
TABLE 1: Vegetable description used in this study.

\begin{tabular}{lccccc}
\hline S. no. & Vegetables & Samples no. & Part 1 & Part 2 & ${ }^{*}$ DMC $(\%)$ \\
\hline 1 & Potato & 28 & Cores & Peels & 22.1 \\
2 & Spinach & 27 & Total & & 7.2 \\
3 & Turnip & 32 & Cores & Peels & 5.3 \\
4 & Carrot & 30 & Cores & Peels & 5.1 \\
5 & Cabbage & 26 & Total & & 6.2 \\
6 & Tomato & 31 & Total & & 4.7 \\
7 & Eggplant & 30 & Cores & Peels & 7 \\
8 & Cucumber & 29 & Cores & Peels & 5.4 \\
9 & Bitter gourd & 26 & Cores & Peels & 5.6 \\
\hline
\end{tabular}

${ }^{*}$ Dry matter content.

responses. All the samples were analyzed for eight $\mathrm{PAH}$ congeners: anthracene, benzo(a)anthracene, benzo(b)fluoranthene, benzo(k)fluoranthene, benzo(a)pyrene, dibenzo(ah)anthracene, benzo(e)pyrene, and dibenzo(ghi)anthracene. These PAH congeners were chosen because of availability of standards and proven carcinogenicity of five of them [3].

Recoveries of PAHs from vegetables by this method were tested by analyzing vegetable samples spiked at the level of 5time limits. The PAH standards were spiked into the samples after the homogenization step. Peak identities were confirmed by running samples and standards under identical conditions [11].

\section{Results}

The mean concentrations of PAHs in selected vegetables are presented in Table 2 on fresh weight basis. Normally vegetables are consumed as fresh; therefore discussion here will be based on the results expressed on a fresh weight basis. The fact that almost all samples in the current study contained PAHs demonstrates the widespread nature of these persistent compounds. A look at total PAH contents reveals that root vegetables like potato and carrot showed higher values ( $13 \mu \mathrm{g} / \mathrm{kg}$ ), whereas turnip showed relatively lower contents at $(10.9 \mu \mathrm{g} / \mathrm{kg})$. For the fruit vegetables, all the peels were found to be more contaminated than cores. The ratios of total $\mathrm{PAH}$ concentrations in peels to those of cores are 1.45, 1.26, $1.31,1.44,1.40$, and 1.36 for potato, turnip, carrot, eggplant, cucumber and bitter gourd, respectively. It can fairly be concluded that peeling of root and fruit vegetables and the removal of outer part of the leafy crop can substantially reduce the ingestion of these compounds. Samsøe-Petersen et al. [17] have reported elevated levels of $\mathrm{B}(\mathrm{a}) \mathrm{P}$ in potato, lettuce, and carrot with peel. For leafy vegetables, spinach and cabbage were analyzed as a whole. Maximum PAH level was shown by cabbage $(11.6 \mu \mathrm{g} / \mathrm{kg})$, which turned out to be more than any of the cores of fruit vegetables. Similar levels $(11.5 \mu \mathrm{g} / \mathrm{kg})$ were shown by spinach as well. These results demonstrated that due to large surface area of cabbage and spinach leaves, the absorption of airborne PAH was quite higher. This is also in accordance with Joint FAO/WHO Expert Committee on Food Additives, whereby, the PAHs that are airborne (either in the vapor phase or adhered to the particulate matter) become deposited on crops, especially crops with broad leaves [18]. Among individual PAH congeners, Ant showed higher levels in all vegetables. For $\mathrm{B}(\mathrm{a}) \mathrm{A}$, maximum concentration $(3.44 \pm 2.10 \mu \mathrm{g} / \mathrm{kg})$ was encountered in turnip cores. Highest $\mathrm{B}(\mathrm{e}) \mathrm{P}$ concentration was found in potato $(3.19 \pm 1.67 \mu \mathrm{g} / \mathrm{kg})$ followed by turnip $(2.74 \pm$ $1.22 \mu \mathrm{g} / \mathrm{kg}) . \mathrm{B}(\mathrm{b}) \mathrm{F}$ and $\mathrm{B}(\mathrm{k}) \mathrm{F}$ showed relatively lower levels in all samples studied. $\mathrm{D}(\mathrm{ah}) \mathrm{A}$ could not be detected in spinach, carrot, and tomato, whereas $\mathrm{B}$ (ghi)P could not be detected in bitter gourd, turnip, carrot, and eggplant. Both are declared carcinogens [3]. Zhong and Wang [11] have reported B(a)A levels in cabbage $(5.46 \pm 10.8 \mu \mathrm{g} / \mathrm{kg})$, cucumber $(2.33 \pm$ $2.02 \mu \mathrm{g} / \mathrm{kg})$ and eggplant $(2.39 \pm 1.82 \mu \mathrm{g} / \mathrm{kg})$ grown in China. Rojo Camargo and Toledo [10] have reported $\mathrm{B}(\mathrm{e}) \mathrm{P}$ and $\mathrm{B}(\mathrm{a}) \mathrm{P}$ levels in cabbage grown in Brazil. Their results for $\mathrm{B}(\mathrm{e}) \mathrm{P}$ $(2.10 \pm 1.21 \mu \mathrm{g} / \mathrm{kg})$ were comparable to our findings, whereas $\mathrm{B}(\mathrm{a}) \mathrm{P}$ levels $(0.12 \pm 0.08 \mu \mathrm{g} / \mathrm{kg})$ were comparable to levels in Pakistani tomato $(0.11 \pm 0.06 \mu \mathrm{g} / \mathrm{kg})$. The detection limits for all eight PAHs found from this study on fresh weight basis are: Ant $(0.22 \mu \mathrm{g} / \mathrm{kg}), \mathrm{B}(\mathrm{a}) \mathrm{A}(0.18 \mu \mathrm{g} / \mathrm{kg}), \mathrm{B}(\mathrm{e}) \mathrm{P}(0.09 \mu \mathrm{g} / \mathrm{kg})$, $\mathrm{B}(\mathrm{b}) \mathrm{F}(0.24 \mu \mathrm{g} / \mathrm{kg}), \mathrm{B}(\mathrm{k}) \mathrm{F}(0.76 \mu \mathrm{g} / \mathrm{kg}), \mathrm{B}(\mathrm{a}) \mathrm{P}(0.11 \mu \mathrm{g} / \mathrm{kg})$, $\mathrm{D}(\mathrm{ah}) \mathrm{A}(0.17 \mu \mathrm{g} / \mathrm{kg})$, and $\mathrm{B}(\mathrm{ghi}) \mathrm{P} 92(0.20 \mu \mathrm{g} / \mathrm{kg})$, respectively.

\section{Discussion}

Irrespective of pathways of such accumulation, information on potential exposure of PAHs is of particular interest due to the fact that general population is most frequently exposed to $\mathrm{PAH}$ through food. The present study analyzed the average PAHs potential to human exposure through vegetables; in order to accomplish this, the mean $\mathrm{PAH}$ concentrations in vegetables were used in combination with average daily consumption of the vegetables and the estimated average of daily consumption of the different vegetables studied by adult population in Punjab, Pakistan, (with the cooperation of Nutrition Division, National Institute of Health (NIH) Pakistan), showed that the consumption of potato was maximum $(75 \mathrm{~g} / \mathrm{p} / \mathrm{d})$, followed by carrot $(60 \mathrm{~g} / \mathrm{p} / \mathrm{d})$, and cabbage $(55 \mathrm{~g} / \mathrm{p} / \mathrm{d})$. Incidentally, potato contained the maximum total PAHs levels as well. Therefore, among the vegetables studied potato $(1.157 \mu \mathrm{g} / \mathrm{p} / \mathrm{d})$ was the biggest source of PAHs exposure (Table 3), followed by carrot $(0.812 \mu \mathrm{g} / \mathrm{p} / \mathrm{d})$, and cabbage $(0.629 \mu \mathrm{g} / \mathrm{p} / \mathrm{d})$. According to a food survey carried out in The Netherlands, the total dietary intake of $\mathrm{B}(\mathrm{a}) \mathrm{P}$ was $0.12-0.29 \mu \mathrm{g} / \mathrm{day}$; in the same study, the maximum concentrations of $\mathrm{B}(\mathrm{a}) \mathrm{P}$ in leafy vegetable and potato were $0.2 \mu \mathrm{g} / \mathrm{kg}$ and $0.4 \mu \mathrm{g} / \mathrm{kg}$, respectively. An estimated value for the average human intake of $\mathrm{B}(\mathrm{a}) \mathrm{P}$ in the United Kingdom in 1979 was $0.25 \mu \mathrm{g} / \mathrm{kg}$, and in Italy the daily intake of $\mathrm{B}(\mathrm{a}) \mathrm{P}$ from food was $0.17 \mu \mathrm{g} / \mathrm{kg}$ [19-21]. These reported values, although older, are similar to our findings.

However, it should be noted that these calculations are based upon the fact that vegetables are consumed raw; but in fact vegetables are cooked, which may substantially affect the final PAH content of eaten vegetables. According to food habits of Pakistani people, cucumber, carrot, cabbage, and 
TABLE 2: Concentrations ( $\mu \mathrm{g} / \mathrm{kg}$; fresh weight) of various PAHs in vegetable parts.

\begin{tabular}{lccccccccccc}
\hline Vegetable & Parts & Ant & $\mathrm{B}(\mathrm{a}) \mathrm{A}$ & $\mathrm{B}(\mathrm{e}) \mathrm{P}$ & $\mathrm{B}(\mathrm{b}) \mathrm{F}$ & $\mathrm{B}(\mathrm{k}) \mathrm{F}$ & $\mathrm{B}(\mathrm{a}) \mathrm{P}$ & $\mathrm{D}(\mathrm{ah}) \mathrm{A}$ & $\mathrm{B}(\mathrm{ghi}) \mathrm{P}$ & $\Sigma \mathrm{PAH}$ \\
\hline \multirow{2}{*}{ Potato } & Cores & $2.88 \pm 2.50$ & $1.18 \pm 0.17$ & $3.19 \pm 1.67$ & $1.44 \pm 1.10$ & $1.12 \pm 1.33$ & $1.75 \pm 1.22$ & $0.32 \pm 0.11$ & $1.12 \pm 1.07$ & 13 \\
& Peels & $4.70 \pm 3.80$ & $2.53 \pm 0.38$ & $4.32 \pm 2.53$ & $1.67 \pm 1.22$ & $1.76 \pm 0.43$ & $2.13 \pm 1.34$ & $0.38 \pm 0.16$ & $1.47 \pm 0.96$ & 18.9 \\
Spinach & Total & $3.17 \pm 2.15$ & $1.79 \pm 1.24$ & $1.76 \pm 1.17$ & $0.89 \pm 0.54$ & $0.87 \pm 0.33$ & $2.45 \pm 1.12$ & nd & $0.57 \pm 0.38$ & 11.5 \\
& Cores & $1.87 \pm 1.65$ & $3.44 \pm 2.10$ & $2.74 \pm 1.22$ & $1.06 \pm 1.11$ & $0.65 \pm 0.34$ & $1.19 \pm 0.88$ & nd & nd & 10.9 \\
Turnip & Peels & $2.13 \pm 1.19$ & $3.30 \pm 1.29$ & $2.98 \pm 1.37$ & $2.34 \pm 0.76$ & $0.73 \pm 0.68$ & $2.10 \pm 1.12$ & $0.19 \pm 0.03$ & nd & 13.8 \\
& Cores & $2.11 \pm 1.62$ & $2.87 \pm 2.13$ & $2.10 \pm 0.86$ & $2.12 \pm 1.13$ & $1.15 \pm 1.12$ & $3.17 \pm 2.13$ & nd & nd & 13.5 \\
Carrot & Peels & $2.79 \pm 2.32$ & $3.49 \pm 3.16$ & $3.16 \pm 1.19$ & $2.69 \pm 1.32$ & $2.05 \pm 1.67$ & $3.64 \pm 2.89$ & nd & nd & 17.8 \\
Cabbage & Total & $3.35 \pm 3.22$ & $1.14 \pm 0.15$ & $1.88 \pm 0.96$ & $0.57 \pm 0.49$ & $0.49 \pm 0.11$ & $1.87 \pm 0.95$ & nd & $2.15 \pm 0.45$ & 11.6 \\
Tomato & Total & $4.45 \pm 3.80$ & $1.86 \pm 0.17$ & $1.25 \pm 0.76$ & $0.15 \pm 0.07$ & $0.17 \pm 0.08$ & $0.11 \pm 0.06$ & nd & $0.94 \pm 0.11$ & 8.9 \\
\multirow{2}{*}{ Eggplant } & Cores & $1.18 \pm 2.87$ & $2.14 \pm 1.3$ & $1.66 \pm 0.65$ & $0.87 \pm 0.52$ & $1.32 \pm 0.56$ & $1.98 \pm 1.12$ & $0.18 \pm 0.07$ & nd & 9.3 \\
& Peels & $2.77 \pm 2.10$ & $3.40 \pm 1.2$ & $2.13 \pm 0.11$ & $1.22 \pm 0.46$ & $1.65 \pm 1.11$ & $1.99 \pm 0.98$ & $0.21 \pm 0.05$ & nd & 13.4 \\
Cucumber & Cores & $0.90 \pm 0.24$ & $1.87 \pm 0.77$ & $1.43 \pm 1.12$ & $0.98 \pm 0.66$ & $0.97 \pm 0.55$ & $2.35 \pm 0.86$ & $0.33 \pm 0.05$ & $0.78 \pm 0.56$ & 9.6 \\
& Peels & $1.36 \pm 0.88$ & $2.46 \pm 1.2$ & $2.32 \pm 0.88$ & $1.12 \pm 0.45$ & $1.54 \pm 0.89$ & $2.88 \pm 0.56$ & $0.67 \pm 0.13$ & $1.13 \pm 0.77$ & 13.5 \\
\multirow{2}{*}{ Bitter gourd } & Cores & $0.65 \pm 0.81$ & $0.76 \pm 0.32$ & $0.67 \pm 0.44$ & $0.87 \pm 0.21$ & $0.67 \pm 0.34$ & $1.33 \pm 0.44$ & $0.85 \pm 0.21$ & nd & 5.8 \\
& Peels & $0.85 \pm 0.43$ & $0.84 \pm 0.09$ & $0.88 \pm 0.12$ & $1.33 \pm 0.76$ & $0.71 \pm 0.64$ & $2.11 \pm 0.17$ & $1.17 \pm 0.87$ & nd & 7.9 \\
\hline
\end{tabular}

nd: not detected.

TABLE 3: Average consumption of vegetables versus potential exposure of PAHs ( $\mu \mathrm{g} / \mathrm{p} / \mathrm{d})$.

\begin{tabular}{lcccccccccc}
\hline Vegetable & Consumption $(\mathrm{g} / \mathrm{p} / \mathrm{d})$ & $\mathrm{Ant}$ & $\mathrm{B}(\mathrm{a}) \mathrm{A}$ & $\mathrm{B}(\mathrm{e}) \mathrm{P}$ & $\mathrm{B}(\mathrm{b}) \mathrm{F}$ & $\mathrm{B}(\mathrm{k}) \mathrm{F}$ & $\mathrm{B}(\mathrm{a}) \mathrm{P}$ & $\mathrm{D}(\mathrm{ah}) \mathrm{A}$ & $\mathrm{B}(\mathrm{ghi}) \mathrm{P}$ & $\Sigma \mathrm{PAH}$ \\
\hline Potato & $\mathbf{7 5}$ & 0.216 & 0.089 & 0.239 & 0.108 & 0.084 & 0.131 & 0.024 & 0.084 & 1.157 \\
Spinach & $\mathbf{4 5}$ & 0.142 & 0.081 & 0.079 & 0.040 & 0.039 & 0.110 & nd & 0.026 & 0.517 \\
Turnip & $\mathbf{5 0}$ & 0.094 & 0.172 & 0.137 & 0.053 & 0.033 & 0.059 & nd & nd & 0.549 \\
Carrot & $\mathbf{6 0}$ & 0.127 & 0.172 & 0.126 & 0.127 & 0.069 & 0.190 & nd & nd & 0.812 \\
Cabbage & $\mathbf{5 5}$ & 0.184 & 0.063 & 0.103 & 0.031 & 0.027 & 0.103 & nd & 0.118 & 0.629 \\
Tomato & $\mathbf{4 5}$ & 0.200 & 0.084 & 0.056 & 0.007 & 0.008 & 0.005 & nd & 0.042 & 0.402 \\
Eggplant & $\mathbf{3 5}$ & 0.041 & 0.075 & 0.058 & 0.030 & 0.046 & 0.069 & 0.006 & nd & 0.325 \\
Cucumber & $\mathbf{3 7}$ & 0.033 & 0.069 & 0.053 & 0.036 & 0.036 & 0.087 & 0.012 & 0.029 & 0.355 \\
Bitter gourd & $\mathbf{4 3}$ & 0.028 & 0.033 & 0.029 & 0.037 & 0.029 & 0.057 & 0.037 & nd & 0.250 \\
\hline Total & $\mathbf{4 4 5}$ & 1.065 & 0.838 & 0.880 & 0.469 & 0.371 & 0.811 & 0.079 & 0.299 & 4.996 \\
\hline
\end{tabular}

nd: not detected.

tomato are eaten as raw, without cooking. On the other hand, potato, turnip, spinach, egg plant, and bitter gourd are consumed after thorough cooking. These food habits are typical of Pakistani population. Therefore, the data provided by NIH could be generalized to overall adult population. Keeping this in view, the data obtained from this study should be carefully handled to represent potential PAH exposure to consumers.

\section{Conclusion}

The present study provides a data for eight priority PAHs present in nine varieties of vegetables grown in Punjab (Pakistan). The results show that all the vegetable samples analyzed contained PAHs; however, the levels of these compounds are not yet alarming. But concerned authorities consider these values as indicative and could average to estimate the Pakistani PAHs human exposure, as they are the only data available on dietary intake of PAHs by local population.

\section{Acknowledgments}

The authors are grateful to Scientific Council, Prince Mohammad Bin Fahd University for supporting this work. Thanks are also due to COMSATS Pakistan for supplying standards and interlaboratory comparison of data.

\section{References}

[1] B. M. Lee and G. A. Shim, "Dietary exposure estimation of benzo[a]pyrene and cancer risk assessment," Journal of Toxicology and Environmental Health A, vol. 70, no. 15-16, pp. 1391-1394, 2007.

[2] E. Yoon, K. Park, H. Lee, J. H. Yang, and C. Lee, "Estimation of excess cancer risk on time-weighted lifetime average daily intake of PAHs from food ingestion," Human and Ecological Risk Assessment, vol. 13, no. 3, pp. 669-680, 2007.

[3] IARC, Monograph on the Evaluation of the Carcinogenic Risk of Chemical To Humans, Polynuclear Aromatic Compounds, Part 1: Chemical, Environmental and Experimental Data, 1983.

[4] Q.-Y. Cai, C.-H. Mo, Y. H. Li et al., "Occurrence and assessment of polycyclic aromatic hydrocarbons in soils from vegetable 
fields of the Pearl River Delta, South China," Chemosphere, vol. 68, no. 1, pp. 159-168, 2007.

[5] S. Farooq, S. Ali-Musstjab-Akber-Shah Eqani, R. N. Malik et al., "Occurrence, finger printing and ecological risk assessment of polycyclic aromatic hydrocarbons (PAHs) in the Chenab River, Pakistan," Journal of Environmental Monitoring, vol. 13, pp. 3207-3215, 2011.

[6] A. M. Kipopoulou, E. Manoli, and C. Samara, "Bioconcentration of polycyclic aromatic hydrocarbons in vegetables grown in an industrial area," Environmental Pollution, vol. 106, no. 3, pp. 369-380, 1999.

[7] D. Voutsa and C. Samara, "Dietary intake of trace elements and polycyclic aromatic hydrocarbons via vegetables grown in an industrial Greek area," Science of the Total Environment, vol. 218, no. 2-3, pp. 203-216, 1998.

[8] S. R. Wild, M. L. Berrow, S. P. McGrath, and K. C. Jones, "Polynuclear aromatic hydrocarbons in crops from long-term field experiments amended with sewage sludge," Environmental Pollution, vol. 76, no. 1, pp. 25-32, 1992.

[9] S. Tao, Y. H. Cui, F. L. Xu et al., "Polycyclic aromatic hydrocarbons (PAHs) in agricultural soil and vegetables from Tianjin," Science of the Total Environment, vol. 320, no. 1, pp. 11-24, 2004.

[10] M. C. Rojo Camargo and M. C. F. Toledo, "Polycyclic aromatic hydrocarbons in Brazilian vegetables and fruits," Food Control, vol. 14, no. 1, pp. 49-53, 2003.

[11] W. Zhong and M. Wang, "Some polycyclic aromatic hydrocarbons in vegetables from Northern China," Journal of Environmental Science and Health A, vol. 37, no. 2, pp. 287-296, 2002.

[12] "Scientific opinion of the panel on contaminants in the food chain on a request from the european commission on polycyclic aromatic hydrocarbons in food," The EFSA Journal, vol. 724, pp. $1-4,2008$.

[13] A. Meudec, J. Dussauze, E. Deslandes, and N. Poupart, "Evidence for bioaccumulation of PAHs within internal shoot tissues by a halophytic plant artificially exposed to petroleumpolluted sediments," Chemosphere, vol. 65, no. 3, pp. 474-481, 2006.

[14] Z. L. Zhang, H. S. Hong, J. L. Zhou, and G. Yu, "Phase association of polycyclic aromatic hydrocarbons in the Minjiang River Estuary, China," Science of the Total Environment, vol. 323, no. 1-3, pp. 71-86, 2004.

[15] Y.-C. Wang, M. Qiao, Y.-X. Liu, H. P. H. Arp, and Y.-G. $\mathrm{Zhu}$, "Comparison of polycyclic aromatic hydrocarbon uptake pathways and risk assessment of vegetables from waste-water irrigated areas in northern China," Journal of Environmental Monitoring, vol. 13, no. 2, pp. 433-439, 2011.

[16] D. H. Phillips, "Polycyclic aromatic hydrocarbons in the diet," Mutation Research, vol. 443, no. 1-2, pp. 139-147, 1999.

[17] L. Samsøe-Petersen, E. H. Larsen, P. B. Larsen, and P. Bruun, "Uptake of trace elements and PAHs by fruit and vegetables from contaminated soils," Environmental Science and Technology, vol. 36, no. 14, pp. 3057-3063, 2002.

[18] Evaluation of certain food contaminants, in Proceedings of the 64th meeting of the Joint FAO/WHO Expert Committee on Food Additives (JECFA '05), pp. 8-17, Rome, Italy, 2005.

[19] L. Turrio-Baldassarri, A. Di Domenico, C. La Rocca, N. Iacovella, and F. Rodriguez, "Polycyclic aromatic hydrocarbons in Italian national and regional diets," Polycyclic Aromatic Compounds, vol. 10, no. 1-4, pp. 343-349, 1996.

[20] R. H. De Vos, W. Van Dokkum, A. Schouten, and P. De JongBerkhout, "Polycyclic aromatic hydrocarbons in Dutch total diet samples (1984-1986)," Food and Chemical Toxicology, vol. 28, no. 4, pp. 263-268, 1990.

[21] M. J. Dennis, R. C. Massey, and D. J. McWeeny, "Analysis of polycyclic aromatic hydrocarbons in UK total diets," Food and Chemical Toxicology, vol. 21, no. 5, pp. 569-574, 1983. 

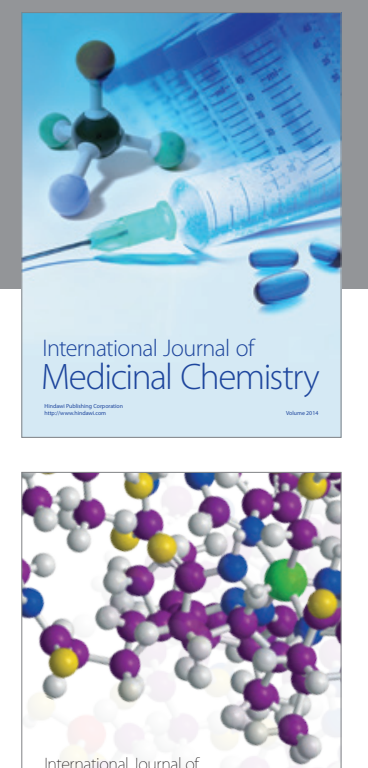

\section{Carbohydrate} Chemistry

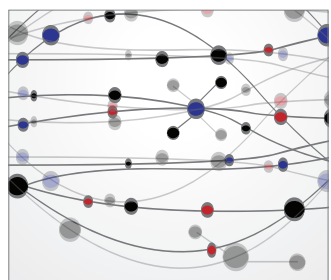

The Scientific World Journal
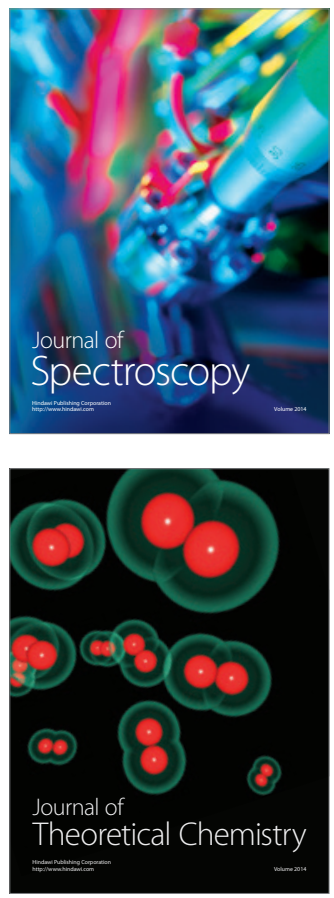
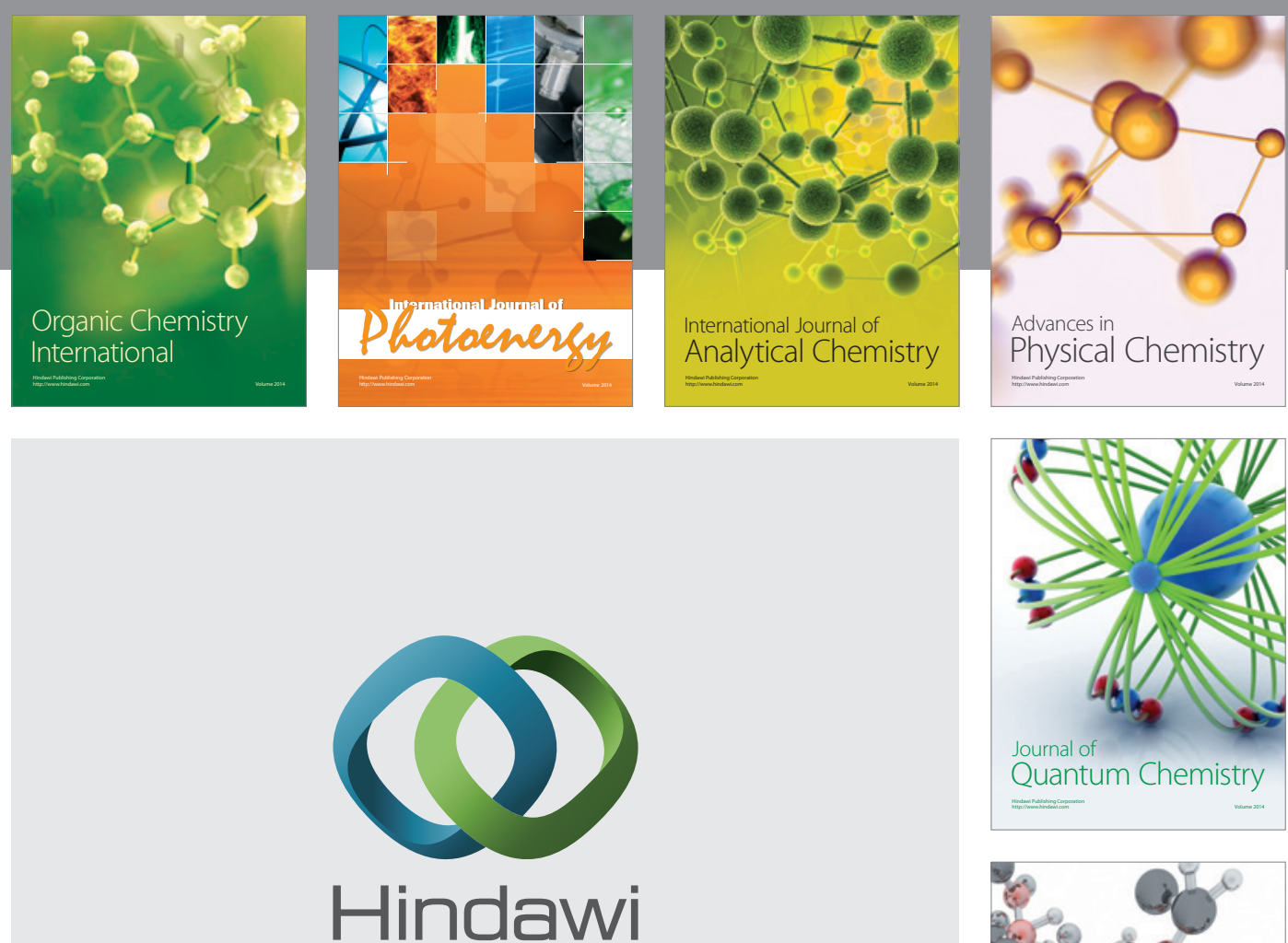

Submit your manuscripts at

http://www.hindawi.com

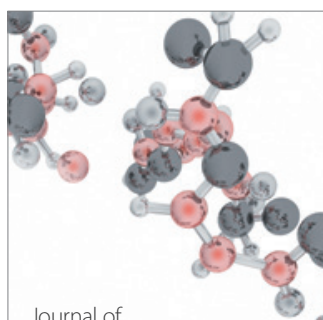

Analytical Methods

in Chemistry

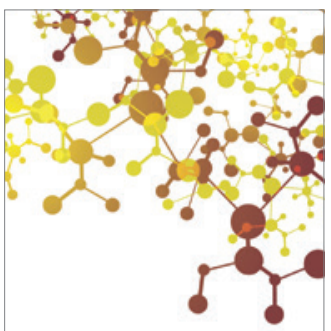

Journal of

Applied Chemistry

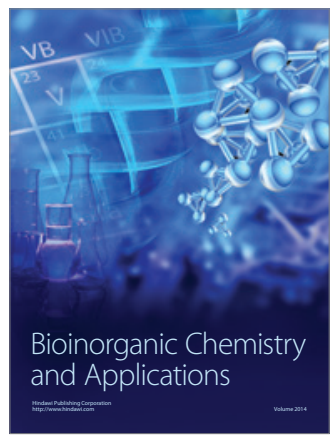

Inorganic Chemistry
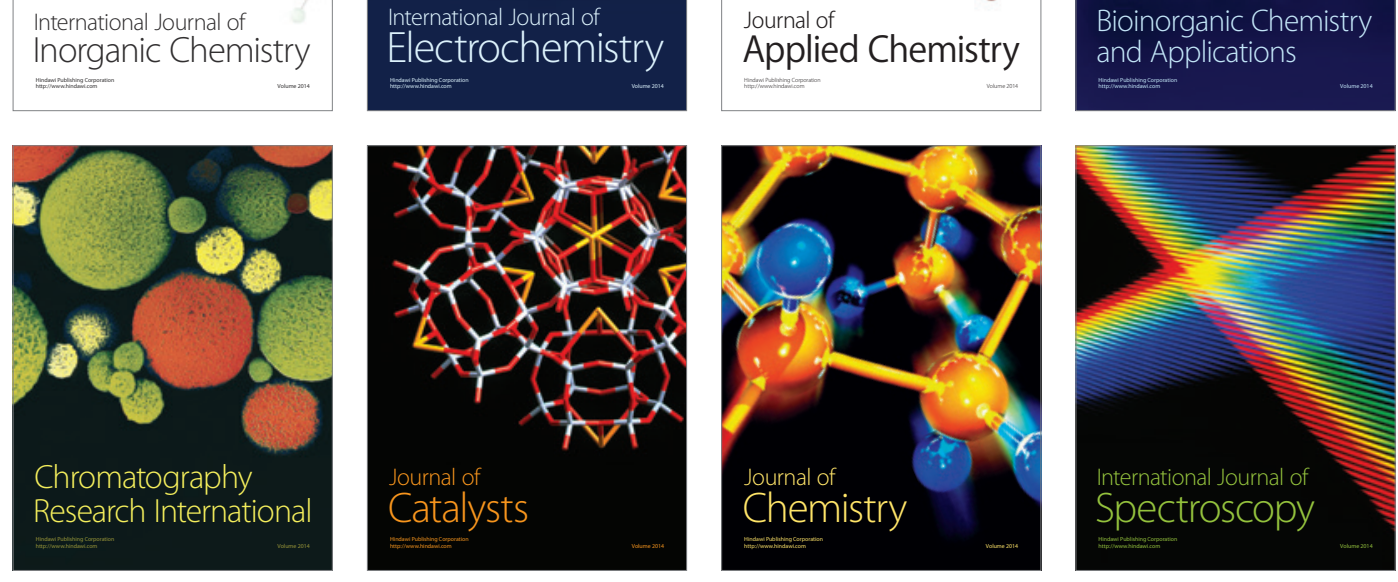